\title{
COLD WORK LOSS DURING HEAT TREATMENT AND EXTRUSION OF NB-46.5WT\%TI COMPOSITES AS MEASURED BY MICROHARDNESS
}

\author{
J.A. Parrell, P. J. Lee, and D.C. Larbalestier \\ Applied Superconductivity Center, University of Wisconsin-Madison \\ 1500 Johnson Drive \\ Madison, WI 53706 USA
}

\begin{abstract}
The quantity, size, and distribution of $\alpha-\mathrm{Ti}$ precipitates are key factors in determining the intrinsic critical current density of $\mathrm{Nb}$ - Ti superconductors. True cold work strains of 5-7 produce a very fine high angle grain boundary structure, in which the favorable precipitate morphology can be nucleated. Optimum high strains cannot be attained within the fabrication strain space of one multifilament billet, and it has therefore recently become common to load multifilament billets with cold worked $\mathrm{Nb}$-Ti rods. Cold work loss occurs in such rods when they are warm $\left(575-625^{\circ} \mathrm{C}\right)$ extruded; moreover, heat treatments may be applied to the monofilaments earlier than the multifilament stacking process, which may further reduce the effective cold work in the $\mathrm{Nb}$-Ti filaments. In this experiment the cold work loss which occurs during monofilament heat treatment and multifilamentary extrusion was directly measured by comparing the Vickers hardness of the same $\mathrm{Nb}-46.5 \mathrm{wt} \% \mathrm{Ti}$ alloy stock which had been cold drawn at room temperature, heat treated and cold drawn, and warm extruded. Depending on the strain state of the filaments prior to extrusion, we determined a strain loss between 1.4-5.4 in the extruded billet filaments. This is a very significant loss range given that the total strain space of most multifilamentary stacks lies in the range of 11-12.
\end{abstract}

\section{INTRODUCTION}

In useful $\mathrm{Nb}-\mathrm{Ti}$ alloys, a high flux pinning force is developed by producing a high volume percent $(\sim 20-25$ vol\%) of extremely small ( $\sim 1 \mathrm{~nm}$ thick, $\sim 200 \mathrm{~nm}$ long, $4 \mathrm{~nm}$ apart) non-superconducting $\alpha$-Ti ribbon-shaped precipitates. ${ }^{[1,2,3]}$ Heat treatment of the wire in the two phase $(\alpha+\beta)$ region produces $\alpha-\mathrm{Ti}$ precipitates, which are drawn into thin ribbons during the cold wire drawing process. These thin, non-superconducting $\alpha$-Ti ribbons act to inhibit fluxon motion, resulting in a high critical current density $\left(J_{c}\right)$. As mentioned above, the maximum flux pinning force (and thus highest $J_{c}$ ) comes from a high volume percent and high number density of small, nanometerthick $\alpha$-Ti precipitates. To obtain a high precipitate number density, a correspondingly high number of heterogenous precipitate nucleation sites are needed. In highly strained $\left(\varepsilon_{\text {truc }}\right.$ $>$ 5) composite wires, the desired nucleation sites are high angle grain boundaries. ${ }^{[1,4,5]}$ Heavy deformation first generates a high dislocation density, then organizes the dislocations into cell walls, and then diminishes the dislocation density as cell walls turn into high angle grain boundaries.

The response of a $\beta-\mathrm{Nb}$-Ti alloy to heat treatments within the $\alpha+\beta$ phase field is strongly dependent on the defect density and structure, as has been reported by Buckett and

This work was supported by the Superconducting Super Collider Laboratory under contract E90703. Manuscript received August $24,1992$.
Larbalestier $^{[5]}$ At low pre-strains (pre-strain is defined as the true deformation strain $\varepsilon=\ln \left(A_{d} / A\right)$ prior to heat treatment, where $A_{o}$ is the cross-sectional area at recrystallization, and $A$ is the cross-sectional area after cold work) of order 2 to 3 , the microstructure contains many types of defects: dislocations within the cell walls, isolated dislocations at cell interiors, and a few high-angle grain boundaries. Nucleation of $\alpha$-Ti occurs on all of these defects, but the Widmanstätten morphology is unfavorable for developing high $\mathrm{J}_{c}$, and $\omega$-phase (which produces high hardness and diminishes ductility) also tends to form within the low dislocation density regions of the grains. Heat treatment within the $\alpha / \alpha+\beta$ phase field should thus be avoided. Buckett and Larbalestier found that a strain of 5 to 7 produced a welldeveloped high angle grain boundary structure in which only grain boundary nucleation of $\alpha$-Ti occurred. However, in a typical manufacturing process there is only a strain space of about 12 available for fabrication of the multifilamentary billet. If a $12^{\prime \prime}(30.5 \mathrm{~cm})$ diameter billet is extruded to $3^{\prime \prime}(7.6 \mathrm{~cm})$ diameter, about one quarter of the strain space is used $\left(\varepsilon_{\mathrm{E}}=2.77\right)$. Normally a strain space of 2.5-3.5 ( $\left.\varepsilon_{\mathrm{HT}}\right)$ is used for the heat treatment phase of wire processing. A final drawing strain $\left(\varepsilon_{\mathrm{F}}\right)$ of order 4.5-5 optimizes $\mathrm{J}_{\mathrm{c}}$ by reducing the 100-200 nm diameter precipitates produced by the last heat treatment to the desired 1-2 nm thickness. These strains cumulatively add to about 10-11, meaning that it becomes hard to extend the extrusion plus cold drawing step prior to the first heat treatment to the 5 to 7 required to suppress Widmanstätten $\alpha$-Ti and $\omega$-phase.

One method used to enhance the effective cold work strain within the microstructure is to load the multifilamentary billet with cold-worked rod. Since it is now common to fabricate $\mathrm{Nb}$ sheathed Nb-Ti starting with an extrusion size of 5-8" (12.7-20.3 $\mathrm{cm}$ ) diameter, it is straightforward to produce $\mathrm{Nb}-\mathrm{Ti}$ rod ready to load into a multifilamentary billet which has a pre-strain of at least 6 . If at least some of this pre-strain can be retained through extrusion, then the strain space available for the multifilament manufacture can be used more effectively. However, extrusion typically takes place at temperatures between $575-625^{\circ} \mathrm{C}$. These temperatures are too low to permit recrystallization of the $\mathrm{Nb}-\mathrm{Ti}$ alloy, but extensive recovery of $\mathrm{Nb}-46.5 \mathrm{wt} \%$ Ti can certainly take place. A second complication comes from the potential that the cold-worked $\beta$-phase $\mathrm{Nb}$ $46.5 \mathrm{wt} \% \mathrm{Ti}$ microstructure may generate $\alpha$-Ti or $\omega$ precipitates during either the pre-extrusion billet warm-up or post-extrusion cool-down stage. It is not clear whether such precipitation would be favorable or detrimental to the subsequent deformation and $\mathrm{J}_{\mathrm{c}}$ properties. A third complication is that heavily cold-worked monofilament rods are very "springy". To ease the multifilament stacking process or for other purposes, some heat treatments may be given to the monofilament at sizes close to the multifilament stack size. The fabrication strain given to the monofilament thus cannot always be relied on as a measure of the effective cold work possessed by the $\mathrm{Nb}$ - $\mathrm{Ti}$ microstructure, since each of the 
above three factors can control the microstructure of the $\mathrm{Nb}-\mathrm{Ti}$. This issue has been little studied. It was the purpose of the present study to utilize the simple technique of hardness measurement as a probe of the retained cold work in variouslytreated $\mathrm{Nb}$-Ti monofilament rod stock, and to compare these results on extruded multifilament rod stock.

\section{EXPERIMENTAL PROCEDURE}

The monofilament and multifilament billet used in this study were supplied by a manufacturer involved with the Phase II Superconducting Super Collider conductor R\&D exercise. The monofilament was manufactured from an annealed 5.75" $(14.6 \mathrm{~cm})$ diameter $\mathrm{Nb}$-Ti ingot. This monofilament was then extruded and cold drawn down to billet stacking size $\left(-0.1^{\prime \prime}\right.$ $(2.54 \mathrm{~mm})$ dia.), and then stacked into a billet at the factory. The multifilament billet had a starting diameter of 12 " $(30.5$ $\mathrm{cm})$, and was warm extruded to a diameter of $3.2^{\prime \prime}(8.13 \mathrm{~cm})$. The monofilament was supplied to us at a diameter of $0.370^{\prime \prime}$ $(9.4 \mathrm{~mm})$, and had been conventionally cold drawn to that point. As we have previously observed ${ }^{[6]}$ that cold work development is not obviously different in extruded and purely cold-worked billets when the extrusion is performed with recrystallized $\mathrm{Nb}-46.5 \mathrm{wt} \% \mathrm{Ti}$, we chose to take the zero of the strain as that size at which the $\mathrm{Nb}$ - $\mathrm{Ti}$ was last recrystallized (i.e. $5.75^{\prime \prime}(14.6 \mathrm{~cm})$ diameter).

Since, as noted above, a variety of processing heat treatments can be applied to monofilaments prior to their being stacked into the multifilament billet, it is not clear whether the above choice of the zero of strain is always appropriate for multifilament $\mathrm{Nb}-\mathrm{Ti}$. To assess what magnitudes of strain loss may occur, we gave our cold drawn monofilaments two different heat treatments at stacking size $\left(\sim 0.1^{\prime \prime}(2.54 \mathrm{~mm})\right.$ dia. $)$ in an attempt to simulate possible conditions of monofilament as it is stacked into the multifilament billet. One heat treatment was a typical precipitation heat treatment $\left(40\right.$ hours at $\left.375^{\circ} \mathrm{C}\right)$, and the other was a recrystallization heat treatment ( 1 hour at $850^{\circ} \mathrm{C}$ ). Thus three different monofilament conditions were tested: 1) As received (extruded and then cold drawn); 2) Precipitation heat treatment at stacking size; 3) Recrystallization heat treatment at stacking size. Except for the heat treatments given to the above two samples, the three monofilament samples were then processed identically.

The monofilament samples at $0.370^{\prime \prime}(9.4 \mathrm{~mm})$ diameter were cold drawn to a diameter of $0: 0179^{\prime \prime}(0.455 \mathrm{~mm})$ (i.e. smaller than the billet stacking size) with dies that produced a $20 \%$ area reduction per pass. Samples of the monofilament wires were taken at every other die size. These samples were prepared for metallography, and then the $\mathrm{Nb}-\mathrm{Ti}$ filament in each sample was indented several times (usually 9 indents per sample) with a Leco Vickers Hardness Tester, using a $200 \mathrm{~g}$ load and a 15 second loading time. To give a more reproducible (and more accurate) hardness value, the projected areas of the multiple hardness indentations in each sample were measured with a high resolution MegaVision image processing system. The resulting average indentation projected area was then converted to a Vickers Hardness Number (VHN) by the usual formula: ${ }^{[7]}$

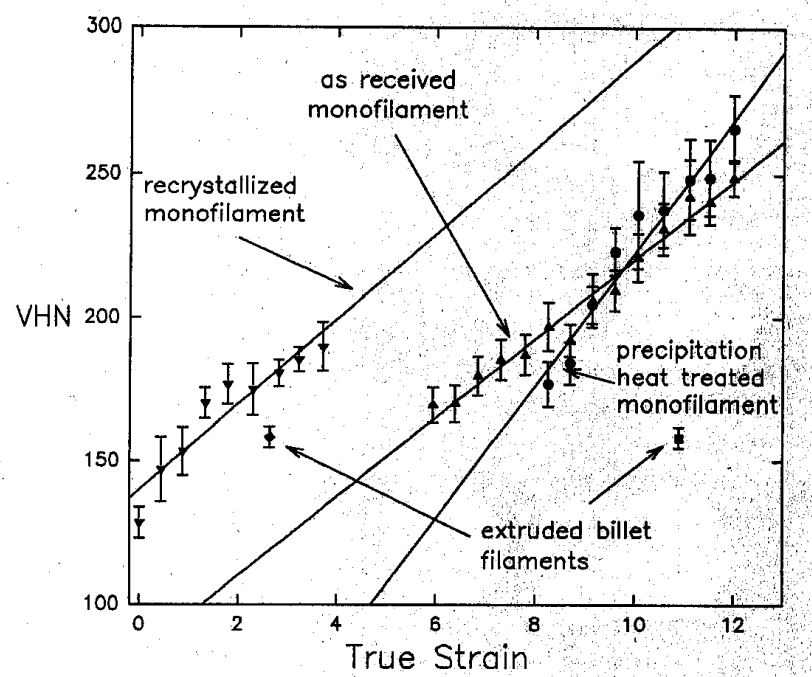

Figure 1. Plot of VHN vs. true strain for the filaments tested. The extruded filament data is plotted twice to reflect two different zeros of strain (see text).

$$
V H N=\frac{0.9272 L}{\text { projected area }}
$$

where $\mathrm{L}=$ load in $\mathrm{kgf}$ and the projected area is in $\mathrm{mm}^{2}$. This was done for each of the monofilament samples, as well as for 15 randomly chosen multifilament billet filaments.

\section{RESULTS}

Figure 1 collects the hardness results obtained in the course of the experiment and correlates them to the fabrication strain of the $\mathrm{Nb}$ - Ti. In the case of the monofilaments, we know the fabrication process and the zero of strain can be correctly assigned to the monofilament extrusion size $\left(5.75^{\prime \prime}(14.6 \mathrm{~cm})\right.$ dia.), since the $\mathrm{Nb}$-Ti was then in the recrystallized state. Due to the difficulties of producing fine grain sizes in large ingots, the average grain size in such ingots is on the order of $60-100$ $\mu^{[8]}$. The monofilament recrystallized at $0.370^{\prime \prime}(9.4 \mathrm{~mm})$ diameter is in a similarly well-defined $\varepsilon=0$ state. The precipitation heat treated sample is clearly not recrystallized by a treatment of 40 hours at $375^{\circ} \mathrm{C}$, and its zero of strain was not changed. However, it is not certain what the correct zero of strain should be for the multifilament billet filaments, since the possibility exists that some thermal treatment was applied to the monofilaments before they were loaded into the multifilament billet. The two extremes of appropriate strain vary from 2.64 (which assumes that the monofilament rods were recrystallized before loading into the billet) to 10.90 (which assumes that no thermal treatments were given). Both possibilities for the extruded filament strain are plotted in Figure 1.

The data of Figure 1 show that hardness measurements can clearly discriminate between the different samples. The two 
single phase monofilament samples have very similar work hardening slopes $(\mathrm{d} \sigma / \mathrm{d} \varepsilon)$. However, the starting hardness at $\varepsilon=0$ is higher for the material recrystallized at small diameter, as would be expected for finer grained material. Figure 2 compares backscatter scanning electron micrographs of the different filament samples. The $\alpha$-Ti precipitates (darker spots) are quite clear in the precipitation heat treated sample, but are absent in the other three (as received cold drawn, recrystallized at stack size, and warm extruded) samples. Some recovery clearly occurred during the precipitation heat treatment, as the hardness dropped from $\sim 190$ to $\sim 170$ VHN. However, the precipitates then substantially increase the work-hardening rate, as expected on general grounds and on the basis of earlier observations of the rate of grain refinement in precipitated $\mathrm{Nb}$ $46.5 \mathrm{wt}^{2} \mathrm{Ti}^{[4]}$.

Comparison of the multifilament hardness data to the monofilament data leads to the same conclusion, whatever the choice of effective strain. If it were the case that the multifilament billet was loaded with recrystallized rod, we would expect a hardness of $\sim 180$ VHN for a cold drawing strain equal to the extrusion strain of 2.64 . Had no thermal treatment been given then the same argument would predict a hardness of $\sim 230 \mathrm{VHN}$. However, the measured hardness of $160 \pm 5 \mathrm{VHN}$ was significantly below both predictions. This indicates that $\mathrm{Nb}$-Ti cold work is indeed lost during the warm extrusion process. From the equations for the linear regression lines fit to the monofilament data points in Figure 1, the strain loss was determined to range from 1.4 to 5.4 .

Since hardness was to be used as a measure of strain, it was necessary to determine if there was any appreciable $\alpha$-Ti precipitation in the extruded billet filaments. Work by Faase, et $a .^{[9]}$ has shown that the use of a scanning electron microscope (SEM) in backscatter imaging mode is a reliable method for determining the volume percent $\alpha$-Ti present in the $\mathrm{Nb}$-Ti filament microstructure. From the results obtained by this method (Figure 2), it did not appear that there was any $\alpha$ Ti precipitate in the extruded filaments (at least none $\sim 10 \mathrm{~nm}$ or greater $)^{[9]}$.

\section{DISCUSSION}

The conditions existing at extrusion remain one of the major unknowns in the $\mathrm{Nb}$-Ti billet manufacturing process. It is important to have a quantitative understanding of the effects of warm extrusion on $\mathrm{Nb}$-Ti cold work strain, since high levels of cold work are vital to getting the highest $\mathrm{J}_{\mathrm{c}}$ out of a composite. Since the optimum level of cold work is greater than the amount of strain possible in a single stack multifilamentary composite, there is every incentive to load the billet with cold worked monofilament rod to increase the effective strain of the composite. However, the use of cold
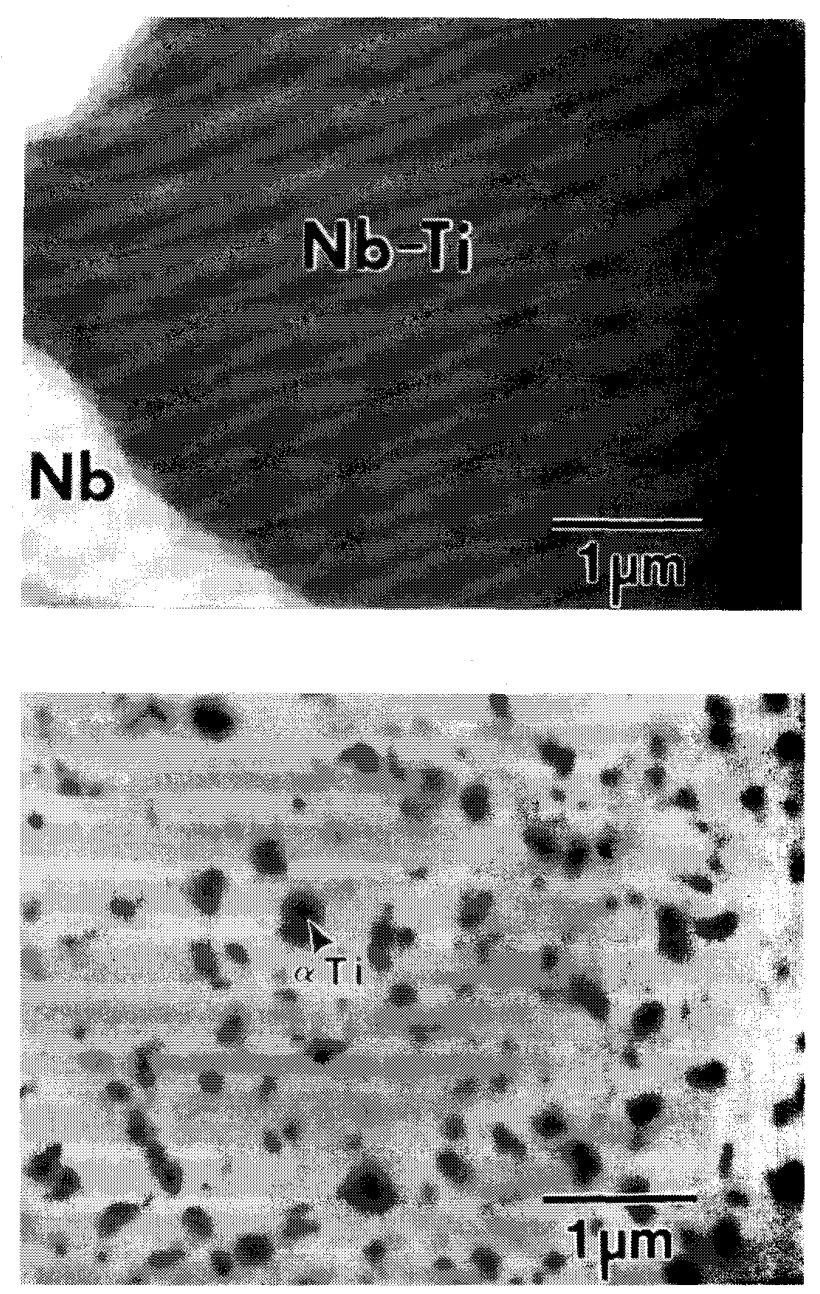

Figure 2. SEM micrographs showing no $\alpha$-Ti precipitation (top, extruded billet), and considerable precipitation (bottom, precipitation heat treated monofilament).

worked monofilaments is only beneficial if useful strain can be retained through extrusion, and if the cold worked monofilaments have no deleterious effects on ease of billet fabrication or composite performance.

The present experiments were aimed at: 1.) Seeing whether Vickers hardness is a useful discriminator of the cold work state in $\mathrm{Nb}$-Ti filaments; 2.) Seeing what a range of typical $\mathrm{Nb}-\mathrm{Ti}$ heat treatments would do to the hardness of $\mathrm{Nb}-\mathrm{Ti}$ monofilaments; and 3.) Comparing these results to those observed on the same material loaded into a multifilament billet whose 
processing conditions were not revealed. Based on the results from this experiment (the linear dependence of hardness on strain), it seems clear that Vickers hardness can indeed be reliably used to judge the cold work strain state of $\mathrm{Nb}-\mathrm{Ti}$ filaments both before and after heat treatment or extrusion. In addition, it was found that any heat treatment given to the monofilament prior to billet stacking causes a substantial initial drop in the hardness of the filaments. This directly translates into a loss of effective cold work strain in the $\mathrm{Nb}$-Ti filaments, which may reduce the multifilament composites' superconducting performance. Thus it appears that it would be best, if possible, to avoid giving monofilaments any thermal treatment prior to billet stacking and extrusion. It was also found that warm extrusion caused a loss of Nb-Ti cold work strain. From the monofilament hardness data, it was determined that the cold work strain loss of the extruded filaments was in the range of 1.4-5.4. This is a considerable strain loss range, considering the fact that the extrusion could only put a maximum strain of about $2.6\left(\varepsilon_{\mathrm{t}}=2 \ln \left(12^{\prime \prime} / 3.2^{\prime \prime}\right)\right)$ into the composite. Since the recrystallization temperature of $\mathrm{Nb}-\mathrm{Ti}$ is about $850^{\circ} \mathrm{C}$ (well above the extrusion temperature of $\sim 575-625^{\circ} \mathrm{C}$ ), any strain loss (drop in hardness) in the extruded filaments must be attributed due to recovery processes occurring within the grains.

Assuming that there was some strain loss caused by the extrusion, this composite likely did not achieve its maximum possible critical current density. ${ }^{[10]}$ Thus, to maximize $\mathrm{J}_{c}$, future composite designs should take into account the strain loss due to extrusion. Increasing the pre-strain in the monofilaments prior to stacking will increase the effective post-extrusion strain; however, there is a penalty to be paid in terms of ease of filament stacking. Hardness testing should provide a useful tool to gauge the effect of monofilament strain state and extrusion conditions on effective heat treatment pre-strain.

\section{CONCLUSIONS}

Warm $\left(-575-625^{\circ} \mathrm{C}\right)$ extrusion is a necessary step in the fabrication of large-scale $\mathrm{Nb}$ - $\mathrm{Ti}$ superconducting composites. This experiment showed Vickers hardness to be useful as a comparative measure of the cold work strain present in heat treated and cold drawn $\mathrm{Nb}$-Ti monofilaments, and extruded $\mathrm{Nb}$ Ti filaments. There was a very strong linear relationship between cold drawing strain and microhardness in the $\mathrm{Nb}-\mathrm{Ti}$ monofilaments, allowing for an estimation of the cold work retained in the extruded multifilamentary conductor. The results of this experiment indicate that cold work loss caused by warm extrusion is a serious concern, since we determined an extrusion strain loss of 1.4-5.4 (depending on the strain state of the filaments prior to extrusion) in the $\mathrm{Nb}-\mathrm{Ti}$ filaments. Vickers hardness and SEM backscatter imaging should yield useful, simple techniques for analysis of this important problem.

\section{ACKNOWLEDGEMENTS}

We would like to thank K. J. Faase, R.W. Heussner, R.M. Scanlan, D.R. Slauson, and W.L. Starch for their assistance.

\section{REFERENCES}

[1] P. J. Lee, D.C. Larbalestier, "Development Of Nanometer Scale Structures In Composites Of Nb-Ti And Their Effect On The Critical Current Density", Acta. Metall, Vol. 35, No. 10, pp. 2523-2536, 1987.

[2] C. Meingast, P. J. Lee, D.C. Larbalestier, "Quantitative Description Of A High $\mathrm{J}_{\mathrm{c}} \mathrm{Nb}$-Ti Superconductor During Its Final Optimization Strain: I. Microstructure, $\mathbf{T}_{c}, \mathbf{H}_{c 2}$, And Resistivity", J. Appl. Phy., Vol. 66, No. 12, pp. 1562 1570, 15 December 1989.

[3] C. Meingast, D.C. Larbalestier, "Quantitative Description Of A High Critical Current Density $\mathrm{Nb}-\mathrm{Ti}$ Superconductor During Its Final Optimization Strain: II. Flux Pinning Mechanisms', J. Appl. Phy., Vol. 66, No. 12, pp. 5971-5982, 15 December 1989.

[4] A.W. West, D.C. Larbalestier, "Microstructural Changes Produced In A Multifilamentary Nb-Ti Composite By Cold Work And Heat Treatment', Met. Trans. A, Vol. 15A, pp. 843-852, May 1984.

[5] M.I. Buckett, D.C. Larbalestier, "Precipitation At Low Strains In Nb-46.5wt\%Ti", IEEE Trans. Magn. Vol. MAG 23, No. 2, pp. 1638-1641, March 1987.

[6] D.C. Larbalestier, A. West, W. Starch, W. Warnes, P. Lee, W.K. McDonald, P. O'Larey, K. Hemachalam, B. Zeitlin, R. Scanlan; C. Taylor, "High Critical Current Densities In Industrial Scale Composites Made From High Homogeneity Nb46.5Ti", IEEE Trans. Magn. Vol. MAG 21, No.2, pp. 269-272, March 1985.

[7] G.F. Vander Voort, Metallography: Principles and Practice, pg. 351, McGraw-Hill, Inc., 1984.

[8] P. J. Lee, D.C. Larbalestier, "A Comparison Of SSC Phase I And Phase II R\&D Strands", 1992 Applied Superconductivity Conference submission.

[9] K. J. Faase, P. J. Lee, D.C. Larbalestier, "Quantification Of Heat Treated NbTi Wire Composite Microstructures With A Scanning Electron Microscope", submitted for publication.

[10] P. J. Lee, J.C. McKinnell, D.C. Larbalestier, "SSC Phase I R\&D Billets OST1836-1 And OST1837-2 Annealed Versus Cold Worked Rod", Superconducting Materials Research Group internal publication. 